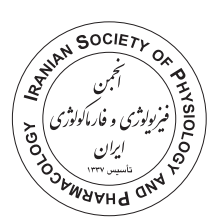

\title{
Hepatoprotective effects of hydroethanolic extracts of Crocus sativus tepals, stigmas and leaves on carbon tetrachloride induced acute liver injury in
}

\section{rats}

Sabir Ouahhoud ${ }^{1 *}$ (iD), Ilham Touiss ${ }^{1}$, Amine Khoulati ${ }^{1}$, Iliass Lahmass ${ }^{1}$, Samira Mamri ${ }^{1}$, Mouhssine Meziane ${ }^{1}$, Soufiane Elassri ${ }^{1}$, Noureddine Bencheikh ${ }^{2}$, Redouane Benabbas ${ }^{1}$, Abdeslam Asehraou $^{1}$, Mohammed Choukri $^{3}$, Ennouamane Saalaoui $^{1}$

1. Laboratory of Biochemistry and Biotechnology, Department of Biology, Faculty of Sciences, University Mohamed Premier, Oujda, Morocco 2. Laboratory of Physiology, Genetics, and Ethnopharmacology, Department of Biology, Faculty of Sciences, University Mohamed Premier, Oujda, Morocco 3. Laboratory of Biochemistry, Central Laboratory Service - CHU, Mohammed VI, Faculty of Medicine and Pharmacy, University Mohamed Premier, Oujda, Morocco

\begin{abstract}
Introduction: The present study investigated the hepatoprotective effects of stigmas, tepals and leaves of Crocus sativus on carbon tetrachloride (CCL4) induced liver injury in rats. Methods: Hydroethanolic extracts of Crocus sativus (stigmas, tepals and leaves) were administrated daily for 14 days by oral gavage. In the present study, 30 male rats divided into five groups were treated as 1: normal rats gavaged with distilled water; 2: intoxicated rats gavaged with distilled water and injected with CCL4; 3 : rats treated with stigmas extract and injected with CCL4; 4: rats treated with tepal extract and injected with CCL4; 5: rats treated with leaf extract and injected with CCL4. Bodyweight and the relative liver weight were determined. Alanine aminotransferase (ALT), aspartate aminotransferase (AST), alkaline phosphatase (ALP), lactate dehydrogenase (LDH), total cholesterol, triglycerides, bilirubin direct and total, total protein, albumin, urea and creatinine measured in plasma. Malondialdehyde (MDA) was quantified in liver homogenate.

Results: The experimental data showed that the stigmas and tepals extracts significantly prevented weight body loss and improved the relative liver weight. They significantly protected against elevation of ALT, AST, direct bilirubin, total bilirubin, LDH, ALP, creatinine and MDA. Also, they enhanced significantly total proteins and albumin compared to the CCL4 control group. Moreover, leaves reduced ALT, AST, total bilirubin, LDH and MDA significantly.

Conclusion: In conclusion, these results suggest that tepals, stigmas, and leaves extracts of Crocus sativus have hepatoprotective effects on CCL4 induced liver injury in rats.
\end{abstract}

\author{
Keywords: \\ Hepatoprotective effects \\ Liver injury \\ CCL4 \\ Crocus sativus L \\ Saffron
}

\footnotetext{
* Corresponding author: Sabir Ouahhoud, s.ouahhoud@ump.ac.ma

Received 27 February 2020; Revised from 6 October 2020; Accepted 12 November 2020

Citation: Ouahhoud S, I Touiss I, A Khoulati, I Lahmass, S Mamri, M Meziane, S Elassri, N Bencheikh, R Benabbas, A Asehraou, M Choukri, E Saalaoui. Hepatoprotective effects of hydroethanolic extracts of Crocus sativus tepals, stigmas and leaves on carbon tetrachloride induced acute liver injury in rats. Physiology and Pharmacology 2021; 25: 178-188. http://dx.doi.org/10.32598/ppj.25.2.30
} 


\section{Introduction}

The liver is an essential organ of the human body. It is involved in multiple functions, such as metabolism, protein synthesis, enzyme secretion and detoxification (Vuda et al., 2012; Koyama and Brenner, 2017). Carbon tetrachloride (CCL4) is a well]-known toxin to induce hepatotoxicity in laboratory animals (Ingawale et al., 2014). Intoxication of CCL4 linked to its metabolites trichloromethyl and trichloromethyl peroxyl formed by cytochrome P450 enzymes (Chiu et al., 2018). These radicals reactive cause a hepatic inflammation (Callewaert et al., 2004; Lin et al., 2014), lipid peroxidation (Basu, 2003), fatty liver and cell necrosis (Recknagel et al., 1989). Protein carbonylation and enzyme disorder are also induced by CCL4 application (Recknagel et al., 1989a). Such perturbations are related to the high affinity of CCL4 metabolites for attachment to cell membrane proteins and lipids (Debnath et al., 2013).

Liver disease remains a global health problem (Ahsan et al., 2009). Unfortunately, conventional drugs used as pharmacotherapy for hepatic disease are expensive and associated with undesirable side effects. Extracts of medicinal plants are considered effective, safe and inexpensive for the treatment of liver disease (Jaishree and Badami, 2010). The Crocus sativus (saffron) belongs to the Iridaceae family. High quantities of organic saffron residues are produced during the processing of stigmas. About $350 \mathrm{~kg}$ of tepals, $1500 \mathrm{~kg}$ of leaves are necessary to obtain just $1 \mathrm{~kg}$ of dry stigmas (Smolskaite et al., 2011). Currently, these by-products are not used and are very little studied. Crocus sativus stigmas have long been used in traditional medicine, cosmetics and as a food additive for coloring and flavoring (Melnyk et al., 2010).

Various studies have shown that saffron stigmas have antioxidant properties (Farahmand et al., 2013), antitumor (Samarghandian and Borji, 2014), antiinflammatory, antidepressant (Lopresti and Drummond, 2014), antitussive (Hosseinzadeh and Ghenaati, 2006), hypolipidemic (Sheng et al., 2006) and could improve memory and learning abilities in rats (Ghadami and Pourmotabbed, 2009; Papandreou et al., 2011). Various beneficial properties of tepals extracts have been reported, including free radical scavenging (Goli et al., 2012; Zeka et al., 2015; Tuberoso et al., 2016), an antidepressant (Moshiri et al., 2006), antinociceptive and anti-inflammatory (Hosseinzadeh and Younesi, 2002; Kumar et al., 2012). They also have chelating metal, cytotoxic and antifungal activities (Zheng et al., 2011; Sánchez-Vioque et al., 2012; Serrano-Díaz et al., 2013).

Smolskaite et al. (2011) reported that saffron leaves considered as a source of bioactive components. Extract of saffron leaves have antioxidant and metal chelating activities (Sánchez-Vioque et al., 2012; Lahmass et al., 2017b). They also have an anti-aging and antiproliferative effect (Sánchez-Vioque et al., 2016; Lahmass et al., 2017a). It has been reported in our laboratory that Crocus sativus by-products have an antihyperglycemic effect and improve the control of diabetes complications such as liver and kidney dysfunction (Ouahhoud et al., 2019). In addition, the presence of bioactive molecules with potent antioxidant properties in Crocus sativus stigmas, tepals and leaves prompted us to design the present study. In this current work, we investigate a comparative research on hepatoprotective effect of hydroethanolic extracts of tepals, leaves and stigmas of Crocus sativus on CCL4-induced acute liver injury in rats.

\section{Materials and methods}

\section{Plant materials}

The stigmas and tepals collected from a farm in Taliouine $\left(30^{\circ} 31^{\prime} 54^{\prime \prime}\right.$ North, $7^{\circ} 55^{\prime} 25^{\prime \prime}$ west-south of Morocco) and therefore the leaves were harvested from a farm in Oujda placement (34 $41^{\prime} 12^{\prime \prime}$ North, $1^{\circ} 54^{\prime} 41^{\prime \prime}$ west-east of Morocco) which the authentic corms received from Taliouine. Saffron of each farm was cultivated without any chemical treatment. The saffron by-products were harvested between October and November (2016). Plant identification has been confirmed by Professor Fennane Mohammed, from Scientific Institute in the capital of Morocco. The plant have been deposited under the voucher number (HUMPOM210) at the Herbarium of University Mohammed first in Oujda, Morocco.

\section{Chemicals}

CCL4 purchased from Sigma chemicals, USA. Alanine aminotransferase (ALT), aspartate aminotransferase (AST), alkaline phosphatase (ALP), lactate dehydrogenase (LDH), bilirubin direct and total, total protein, albumin, total cholesterol, triglycerides, urea 
and creatinine kits were purchased from Roche, France. All other chemicals used in this study were of high quality and analytical grade.

\section{Hydroethanolic extracts preparation}

Stigmas and the other parts of the plant (Crocus sativus) were separated manually. At room temperature, fresh tepals or dried and ground stigmas or leaves were dynamically extracted by maceration under agitation for $24 \mathrm{~h}$ in the dark, with ethanol/water $80 / 20(\mathrm{v} / \mathrm{v})$ at a plant solvent. Then, the mixture was filtered $(0.45 \mu \mathrm{m})$ and the marc recuperated for the second extraction. The protocol repeated three times and the total filtered solvent phase dried at $37^{\circ} \mathrm{C}$ on a rotatory evaporator. Finally, the resulting dried extracts were kept as stable at $-20^{\circ} \mathrm{C}$ until use.

\section{Animals}

Adult male Wistar rats (weight 150-280g) were housed in animal house of the Department of Biology, University of Mohammed First, Morocco and were maintained at constant temperature of $21 \pm 2^{\circ} \mathrm{C}$ during $12 \mathrm{~h}$ light/dark cycle. They fed on a commercial diet (dry rat pellets supplies produced by SONABETAIL Society, Oujda, Morocco) and water throughout the experiments.

This study was following the international standard guidelines for the car and use of laboratory animals.

\section{Experimental procedure}

Hydroethanolic extracts of Crocus sativus (stigmas, tepals and leaves) were administrated daily for 14 days by oral gavage. In the present study, 30 male rats divided into five groups were treated as follows: Group 1: normal rats gavaged with distilled water; Group 2: intoxicated rats gavaged with distilled water and injected with CCL4; Group 3: rats treated with stigma extract and injected with CCL4; Group 4: rats treated with tepal extract and injected with CCL4; Group 5: rats treated with leaf extract and injected with CCL4.

Except for the standard control group, all animals of other groups were received CCL4 intraperitoneally at a dose of $1 \mathrm{ml} / \mathrm{kg}$ body weight (CCL4 dissolved in $25 \%$ olive oil; v/v) at the 7th and 14th days of treatment to induce experimental liver disease. Rats weighed before and after the treatment. All animals treated and observed daily for two weeks.

After twelve hours of final intraperitoneal injection of CCL4, all rats were anesthetized and blood samples were collected from abdominal aorta in Heparin tubes (VACUETTE®). Then, whole blood centrifuged at $3000 \mathrm{~g}$ for separation of plasma. Approximately $2 \mathrm{ml}$ of plasma from every rat has been conserved at $-20^{\circ} \mathrm{C}$ until biochemical assays. After blood collection, the liver was removed and deposited in physiological water, dried on filter paper and weighed. The liver stored at $-20^{\circ} \mathrm{C}$ for the determination of malondialdehyde (MDA).

\section{Biochemical assays}

ALT, AST, ALP, LDH, bilirubin direct and total, total protein, albumin, total cholesterol, triglycerides, urea and creatinine were determined with autoanalyzer from Roche diagnostics (COBAS INTEGRA®).

\section{Determination of $M D A$}

Lipid peroxidation was determined according to the thiobarbituric acid (TBA) protocol (Buege \& Aust, $1978)$ with slight modifications. The liver $(1 \mathrm{~g})$ was homogenized in $5 \mathrm{ml}$ of $\mathrm{PBS}$ buffer $(\mathrm{pH}=7.4)$ and centrifuged at $14500 \mathrm{rpm}$ during $15 \mathrm{~min}$. Then, $2 \mathrm{ml}$ of the reagent $(0.375 \%$ TBA and $15 \%$ trichloroacetic acid dissolved in $0.25 \mathrm{~N}$ hydrochloric acid) was added to $1 \mathrm{ml}$ of the supernatant. Then, samples were putted in water bath regulated on $100^{\circ} \mathrm{C}$ for $30 \mathrm{~min}$ and centrifuged at 4750rpm during $5 \mathrm{~min}$. The absorbance was measured at $535 \mathrm{~nm}$ and the concentration of MDA was calculated using a molar attenuation coefficient 1.56x. The results expressed in nanomoles of MDA produced per milligram of tissue.

\section{Statistical analysis}

Statistical analysis of data realized by one-way ANOVA and groups were compared by Tukey's multiple comparison post-test using GraphPad Prism 5.0 statistical software. The data were expressed as mean $\pm \mathrm{SEM}$ for six rats in each group and with significance levels of $P<0.05, P<0.01$ and $P<0.001$.

\section{Results}

Effect of stigmas, tepals and leaves extracts on the body weight and the relative liver weight

The effects of stigmas, tepals and leaves extracts on the body weight gain and the relative liver weight shown in Figure 1. The CCL4 group showed a significant weight loss $(P<0.001)$ compared to the normal control group. Stigmas $(50 \mathrm{mg} / \mathrm{kg} /$ day $)$ and tepals $(250 \mathrm{mg} /$ 

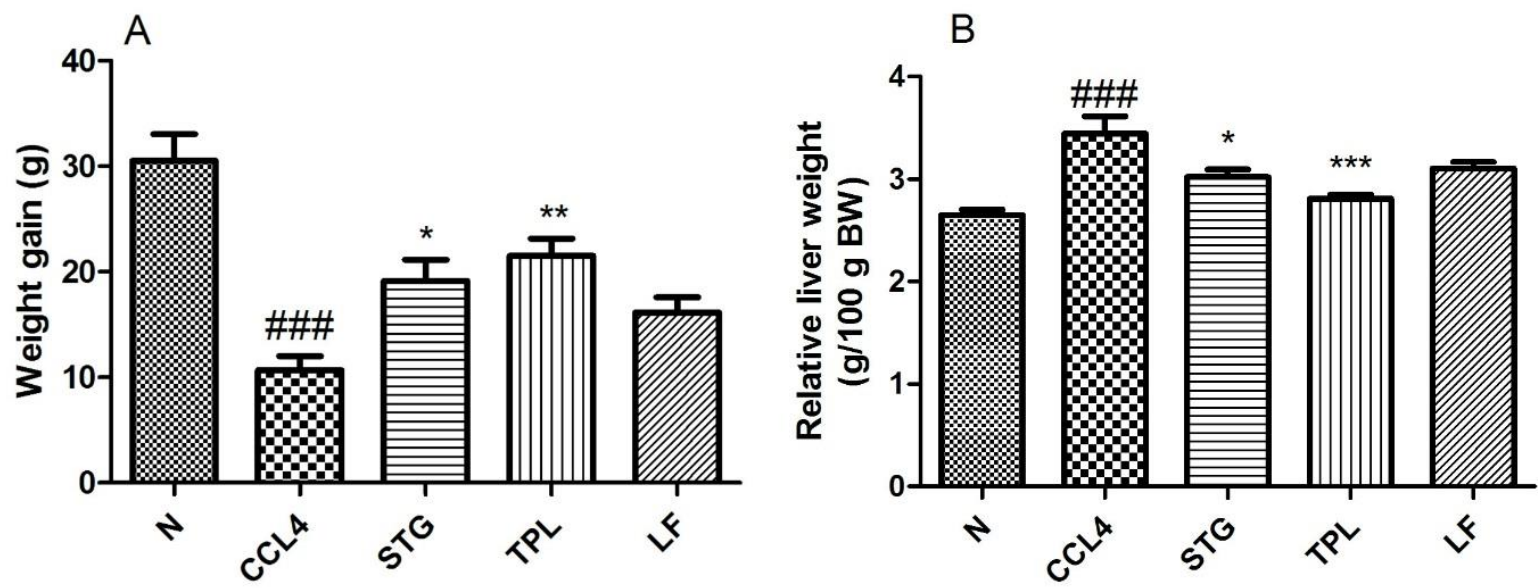

FIGURE 1. Effect of Crocus sativus stigmas (STG, $50 \mathrm{mg} / \mathrm{kg}$ ), tepals (TPL, 250mg/kg) and leaves (LF, 250mg/kg) on the body weight gain (A) and the relative liver weight (B) in CCL4-intoxicated rats. The results are expressed as mean \pm SEM $(\mathrm{n}=6){ }^{\# \#} P<0.001$ compared with normal control group $(\mathrm{N}) ;{ }^{*} P<0.05,{ }^{* *} P<0.01$ and ${ }^{* * *} P<0.001$ compared with CCL4.
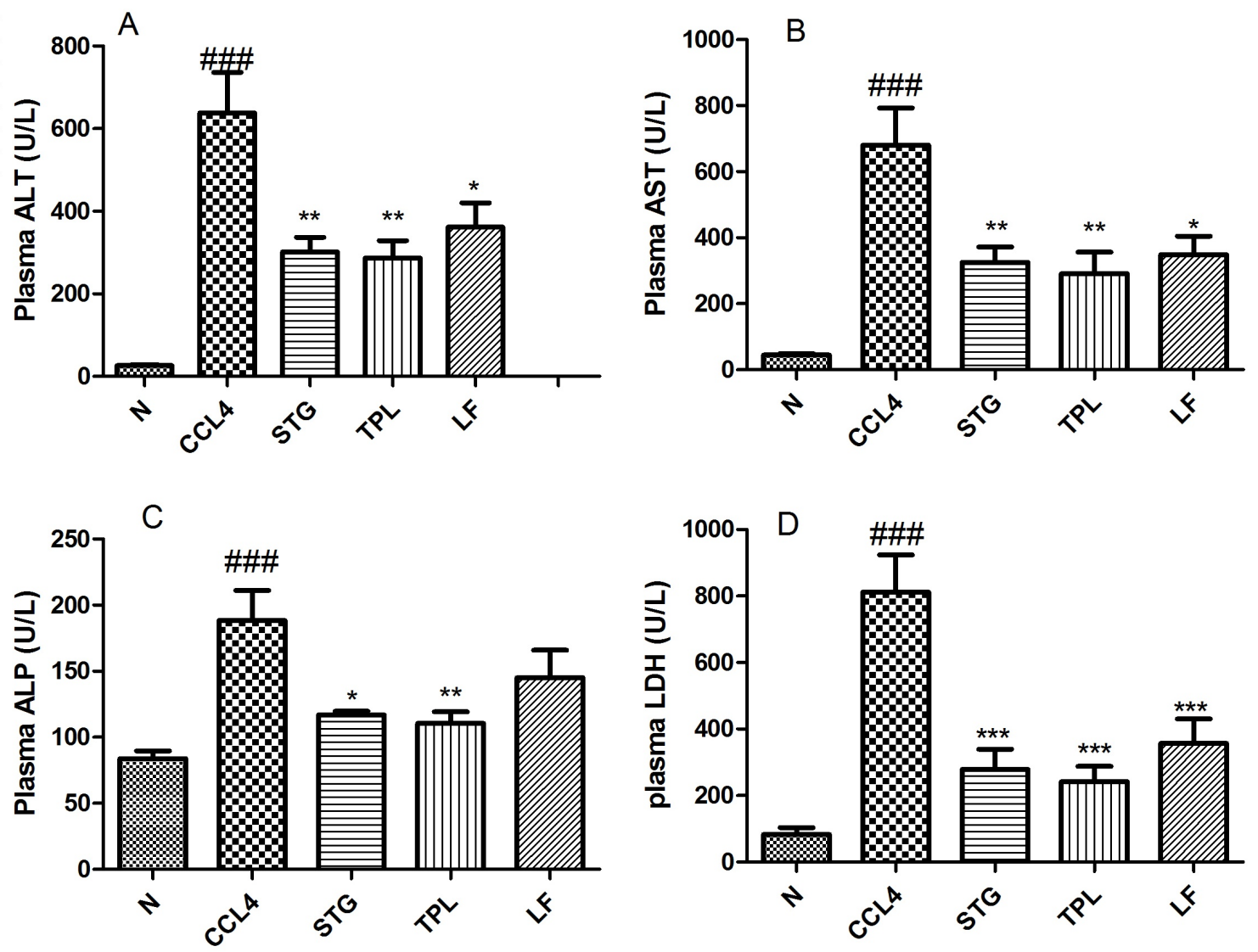

FIGURE 2. Effect of Crocus sativus stigmas (STG, $50 \mathrm{mg} / \mathrm{kg}$ ), tepals (TPL, 250mg/kg) and leaves (LF, 250mg/kg) on plasma levels of (A) alanine aminotransferase (ALT), (B) aspartate aminotransferase (AST), (C) alkaline phosphatase (ALP) and (D) lactate dehydrogenase (LDH) in CCL4-intoxicated rats. The results are expressed as mean $\pm \mathrm{SEM}(\mathrm{n}=6)$. \#\#\#P<0.001 compared with normal control group $(\mathrm{N}){ }^{*} P<0.05$, ${ }^{* *} P<0.01$ and ${ }^{* * *} P<0.001$ compared with CCL4.

$\mathrm{kg} /$ day) extracts significantly protect against weight loss in CCL4 rats $(P<0.05$ and $P<0.01$, respectively) compared to the CCL4 untreated rats. While there was no significant effect on the body weight gain in the group treated with leaves extract $(250 \mathrm{mg} / \mathrm{kg} /$ day $)$. The
CCL4 group showed a significant increase $(P<0.001)$ of relative liver weight compared to the normal group. The treatment with stigmas and tepals extracts decreased significantly the relative liver weight $(P<0.05$ and $P<0.001$, respectively). However, there was no 

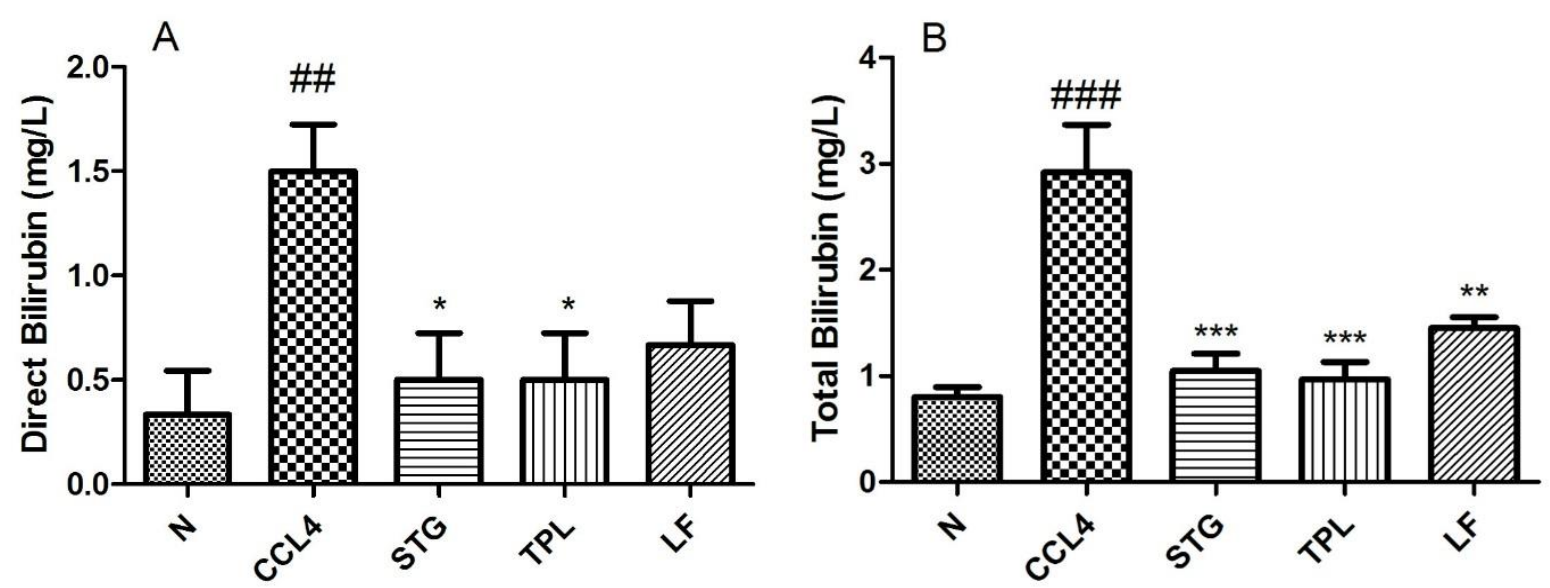

FIGURE 3. Effect of Crocus sativus stigmas (STG, $50 \mathrm{mg} / \mathrm{kg}$ ), tepals (TPL, $250 \mathrm{mg} / \mathrm{kg}$ ) and leaves (LF, 250mg/kg) on plasma levels of direct bilirubin (A) and total bilirubin (B) in CCL4-intoxicated rats. The results are expressed as mean \pm SEM (n=6). ${ }^{\# \# \#<0.001 ; ~}{ }^{\# \#} P<0.01$ compared with normal control (N). ${ }^{*} P<0.05,{ }^{* *} P<0.01$ and ${ }^{* * *} P<0.001$ compared with CCL4.
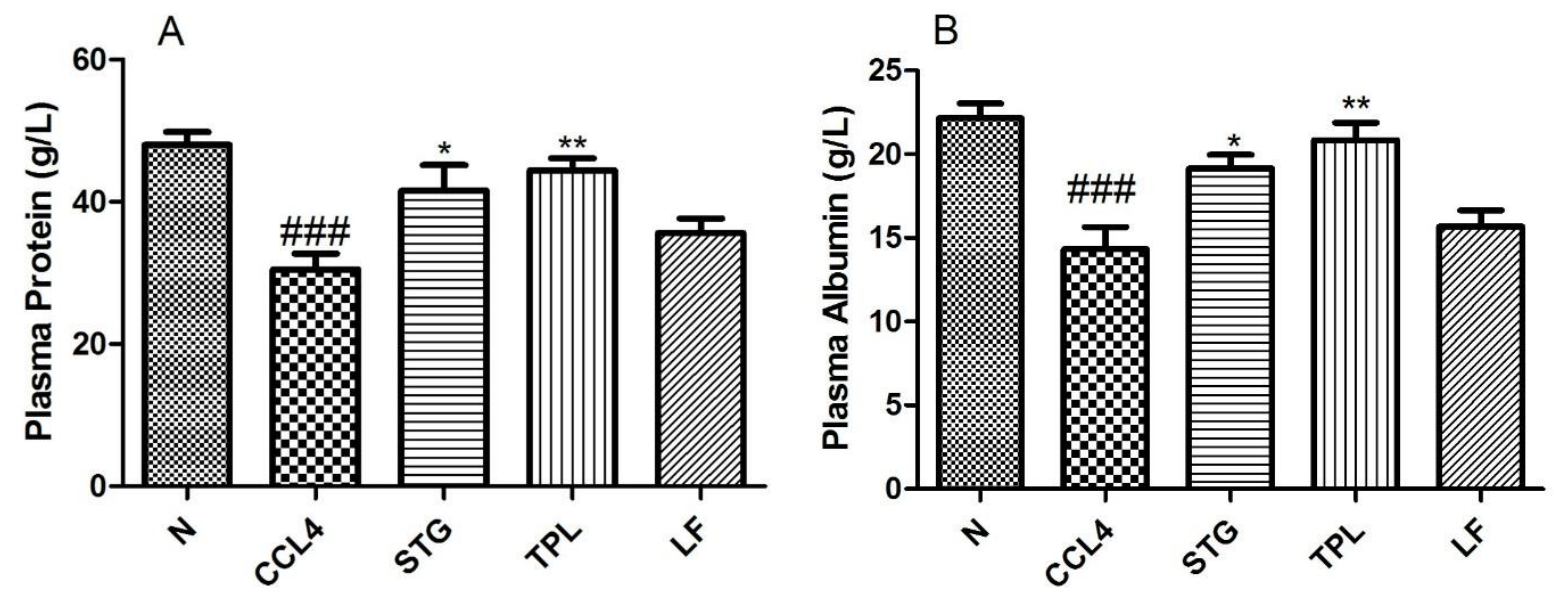

FIGURE 4. Effect of Crocus sativus stigmas (STG, $50 \mathrm{mg} / \mathrm{kg}$ ), tepals (TPL, 250mg/kg) and leaves (LF, 250mg/kg) on plasma levels of total protein (A) and albumin (B) in CCL4-intoxicated rats. The results are expressed as mean $\pm \mathrm{SEM}(\mathrm{n}=6)$. ${ }^{\# \prime \prime} P<0.001$ compared with normal control group $(\mathrm{N}) .{ }^{*} P<0.05,{ }^{* *} P<0.01$ compared with CCL4.

significant effect on the relative liver weight in the group treated with leaf extract.

Effect of stigmas, tepals and leaves extracts on plasma levels of ALT, AST, ALP and LDH

Figure 2 shows the plasma levels of ALT (A) and AST (B) in normal and experimental animals in each group. The CCL4 group showed a significant increase $(P<0.001)$ in the level of plasma ALT and AST compared with the standard control group. The administration of stigmas, tepals and leaves extracts significantly decreased plasma ALT $(P<0.01, P<0.01$ and $P<0.05$, respectively) and plasma AST $(P<0.01, P<0.01$ and $P<0.05$, respectively).

The level of plasma PAL and LDH levels in control normal, control CCL4 and treated CCL4 animals showed in Figure 2 (C and D, respectively). The treatment of rats with CCL4 induced a significant increase in plasma ALP and LDH $(P<0.001)$. In contrast, stigmas and tepals extract significantly decreased plasma ALP $(P<0.05$ and $P<0.01$, respectively) compared to the CCL4 group. Although the leaves extract group did not present a significant decrease. Then, daily administration for 14 days of stigmas, tepals and leaves extracts significantly reduced the plasma LDH level $(P<0.001)$ compared to the CCL4 group.

Effect of stigmas, tepals and leaves extracts on plasma levels of direct bilirubin and total bilirubin

Figure 3 summarizes the plasma levels of direct bilirubin (A) and total bilirubin (B) in normal, CCL4 untreated and CCL4 treated rats. The treatment of 

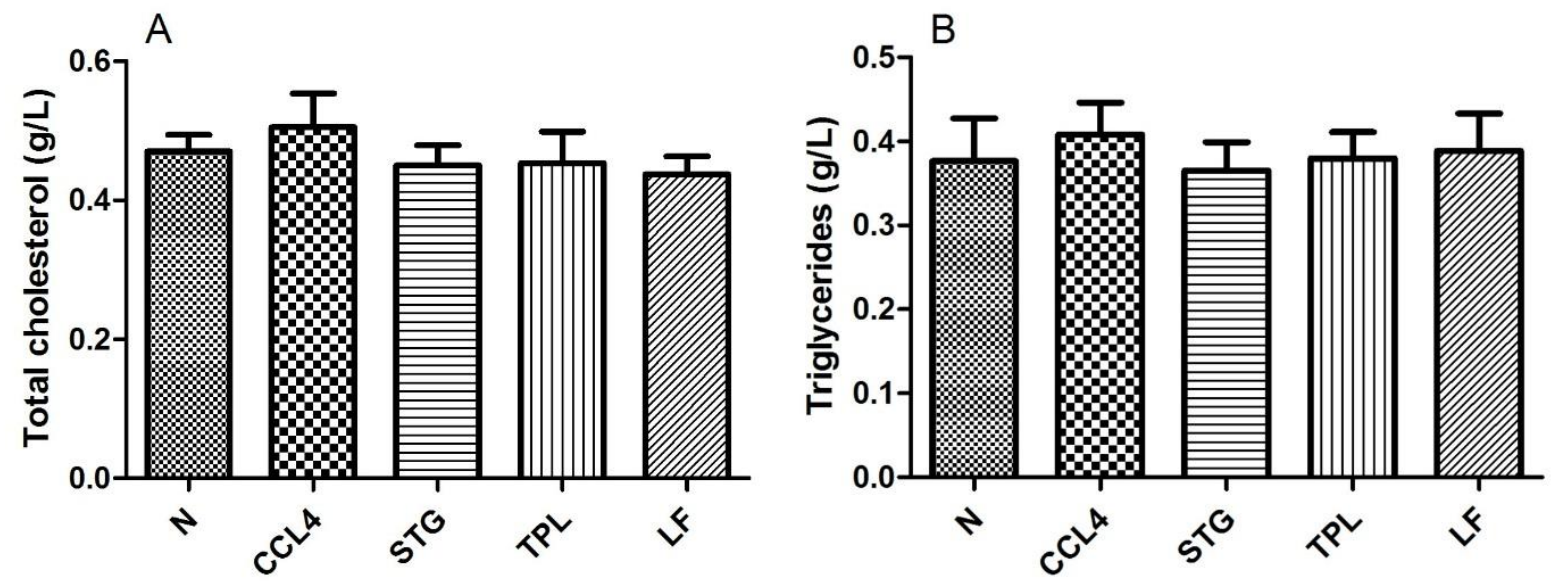

FIGURE 5. Effect of Crocus sativus stigmas (STG, $50 \mathrm{mg} / \mathrm{kg})$, tepals (TPL, 250mg/kg) and leaves (LF, 250mg/kg) on plasma levels of total cholesterol (A) and triglycerides (B) in CCL4-intoxicated rats. The results are expressed as mean \pm SEM ( $\mathrm{n}=6)$.
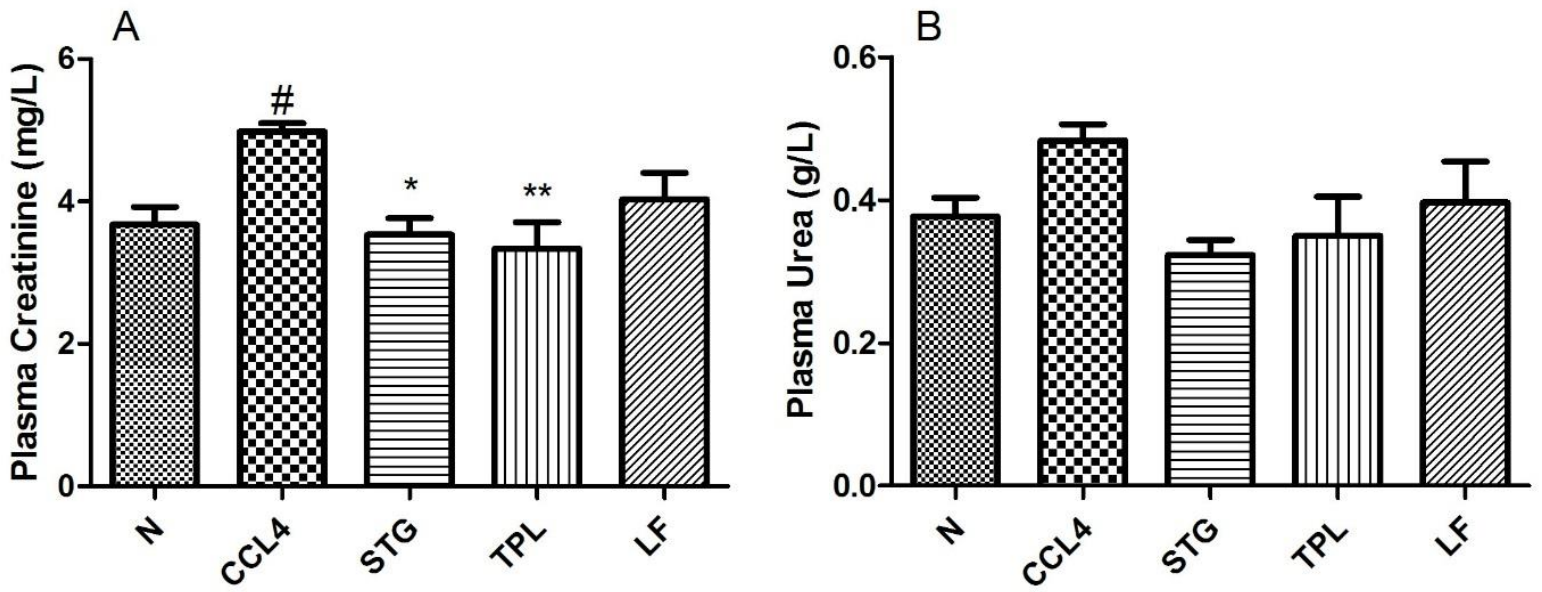

FIGURE 6. Effect of Crocus sativus stigmas (STG, $50 \mathrm{mg} / \mathrm{kg}$ ), tepals (TPL, $250 \mathrm{mg} / \mathrm{kg}$ ) and leaves (LF, $250 \mathrm{mg} / \mathrm{kg}$ ) on plasma levels of creatinine (A) and urea (B) in CCL4-intoxicated rats. The results are expressed as mean $\pm \mathrm{SEM}(\mathrm{n}=6)$. ${ }^{\#} \mathrm{P}<0.05$ compared with normal control group $(\mathrm{N}) .{ }^{*} P<0.05,{ }^{* *} P<0.01$ compared with CCL4.

rats with CCL4, induced a significant elevation in direct plasma bilirubin and total bilirubin $(P<0.01$ and $P<0.001$, respectively). The height of plasma direct bilirubin significantly slowed down after the daily administration of stigmas and tepals extracts $(P<0.05)$. Besides, stigmas, tepals and leaves extracts significantly decreased total plasma bilirubin $(P<0.001, P<0.001$ and $P<0.01$, respectively) compared to the CCL4 group.

Effect of stigmas, tepals and leaves extracts on plasma levels of total proteins and albumin

The levels of plasma total proteins and albumin in control normal, control CCL4 and treated CCL4 animals showed in Figure 4. The treatment of rats with CCL4, induced a significant decrease in plasma total proteins and albumin levels $(P<0.001)$. The administration for
14 days of stigmas and tepals extracts significantly protected against the decrease of the total plasma proteins and albumin levels compared to the CCL4 group $(P<0.05$ and $P<0.01$ respectively). However, there was no significant effect on the total plasma proteins and albumin levels in the group treated with leaf extract.

Effect of stigmas, tepals and leaves extracts on plasma levels of cholesterol and triglycerides

The plasma levels of total cholesterol and triglycerides represented in Figure 5. Results showed that intraperitoneal injection of CCL4 to the rats did not influence the plasma levels of total cholesterol and triglycerides significantly compared with the control group. Furthermore, there was no significant effect on plasma levels of total cholesterol and triglycerides in 


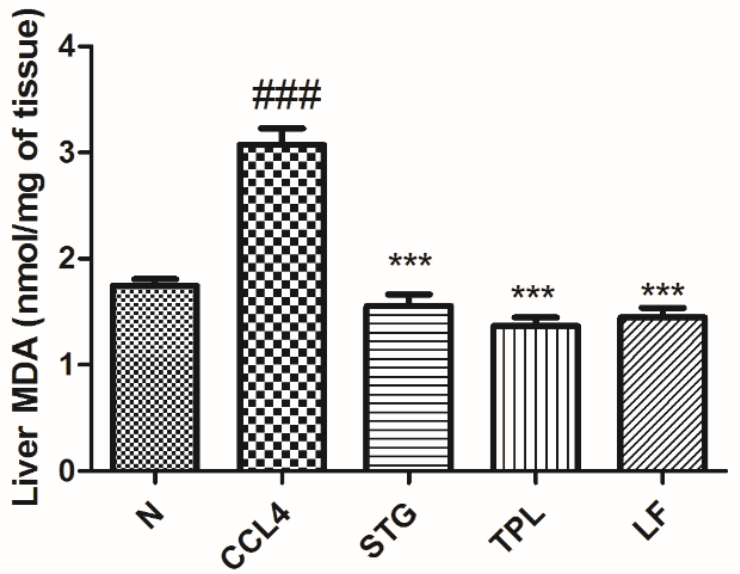

FIGURE 7. Effect of Crocus sativus stigmas (STG, $50 \mathrm{mg} / \mathrm{kg}$ ), tepals (TPL, $250 \mathrm{mg} / \mathrm{kg}$ ) and leaves (LF, $250 \mathrm{mg} / \mathrm{kg}$ ) on liver levels of MDA in CCL4-intoxicated rats. The results are expressed as mean \pm SEM $(\mathrm{n}=6) .{ }^{\# \#} P<0.001$ compared with normal control group $(\mathrm{N}) .{ }^{* * *} P<0.001$ compared with CCL4.

stigmas, tepals and leaves extract groups compared with the CCL4 control group.

Effect of stigmas, tepals and leaves extracts on plasma levels of creatinine and urea

On day 14, the plasma levels of creatinine and urea in normal animals and animals injected with CCL4 in each group shown in Figure 6. Creatinine in plasma increased in untreated CCL4 rats compared with the normal group $(P<0.05)$. The administration of the stigmas and tepals extracts significantly decreased plasma creatinine level $(P<0.05$ and $P<0.01$, respectively). However, there was no significant decrease in the leaves extract group. There was no significant elevation on the plasma urea level between normal and CCL4 control rats. Also, there was no significant decrease in plasma urea levels in the stigmas, tepals and leaves extract groups compared with the CCL4 control group.

Effect of stigmas, tepals and leaves extracts on liver MDA levels

The liver MDA levels in control normal, control CCL4 and treated CCL4 animals showed in Figure 7. The injection of rats with CCL4, induced a significant elevation in liver MDA levels $(P<0.001)$; while a significant decrease in liver MDA levels observed in the stigmas, tepals and leaves extract groups $(P<0.001)$.

\section{Discussion}

The present study illustrated the protective propriety of stigmas, tepals, and leaves of Crocus sativus against CCL4 induced hepatic damage in rats. CCL4 intoxication is a standard model for assessing the hepatoprotective activity of compounds (Recknagel et al., 1989; Manibusan et al., 2007). CCL4 causes rapidly severe hepatic necrosis at single exposure and the pathological damage induced in CCL4 treated animals is similar to the symptoms of cirrhosis in humans (Lin et al., 2014). Hepatotoxicity of CCL4 related to its metabolites trichloromethyl and trichloromethyl peroxyl which are formed by cytochrome P450 enzymes (Chiu et al., 2018). These radicals reactive cause hepatic inflammation (Callewaert et al., 2004; Lin et al., 2014), lipid peroxidation (Basu, 2003), hepatic steatosis, cell necrosis (Recknagel et al., 1989), protein carbonylation and enzyme disorder (Recknagel et al., 1989). Consequently, various species of oxygen radicals are present, including superoxide, hydroxyl radicals and hydrogen peroxide, which can be attached to DNA, proteins and phospholipids, resulting in damage to cell membrane structure and organs (Lin and Huang, 2000).

The results of this study showed that the extract of tepals and stigmas prevented significantly weight loss and enhanced relative liver weight. It significantly protected against elevations of ALT, AST, direct bilirubin, total bilirubin, $\mathrm{LDH}, \mathrm{PAL}$, creatinine and MDA. In addition, they significantly improved total protein and albumin compared to the CCL4 control group. Moreover, the leaves significantly reduced ALT, AST, total bilirubin, LDH and MDA. Various studies indicated that the relative liver weight was a sensitive indicator of hepatotoxicity in a CCL4-induced liver 
damage model (Uemitsu et al., 1986; Wu et al., 2008). An increase in liver weight in CCL4 control rats is likely due to the fat vacuole accumulation revealed by hematoxylin and eosin staining (Wu et al., 2008). The CCL4 group showed a significant loss weight and a significant elevation in relative liver weight compared to the normal control group. While stigmates and tepal extract significantly protected against weight loss and significantly decreased relative liver weight in CCL4 rats compared to the CCL4 group.

Elevated ALT, AST, ALP and LDH levels are specific indices of liver damage (Thabrew et al., 1987).The present data showed a significant elevation in the plasma levels of ALT, AST, ALP, and LDH in CCL4 group, indexing the damage on hepatic cells (Lee et al., 2007; Kale et al., 2012). However, the plasma ALT, AST and LDH activities significantly declined by treatment with tepals, stigmas and leaves extracts. Also, the plasma ALP was significantly reduced by treatment with tepals and stigmas extracts. Bilirubin is the product of heme catabolism, produced during the destruction of old or abnormal erythrocytes. Its elevation considered a clinical index of the binding, hepatobiliary disease and excretory capacity of liver cells (Martin, 1992; Vuda et al., 2012). Our data revealed a significant elevation of direct bilirubin and total bilirubin in plasma rat on exposure to CCL4. Whereas, administration of tepals, stigmas and leaves extracts restored the levels of total bilirubin in plasma rat. Then, our extracts may reflect protection against the hepatic damage caused by CCL4.

In this study, total protein and albumin levels in plasma were also measured. The decrease in total protein and albumin levels may be due to liver dysfunction. Albumin synthesized in the liver, and its measurement employed to control the liver dysfunction (Friedman et al., 1980). Reduced level of total protein and albumin were observed in CCL4 group, which indicate the liver dysfunction. While the treatment with tepals and stigmas significantly restored the protein content. Our study showed that CCL4 had no effect on increasing plasma levels of total cholesterol and triglycerides. Moreover, there was no significant effect on total cholesterol and triglyceride plasma levels in the tepals, stigmas and leaves extract groups compared to the CCL4 group.

These results are in agreement with those of Byun et al. (2018) which found that CCL4 administration had no significant effect on plasma total cholesterol and triglyceride levels. Urea and creatinine are considered an indicator of renal dysfunction (Perrone et al., 1992; Burtis et al., 1999). This finding indicates that CCL4 control rats increased plasma creatinine levels significantly. However, this marker was decreased in hepatotoxic rats treated with tepals and stigmas extracts. While, there was no significant increase in plasma urea levels in CCL4 rats.

Studies have shown that lipid peroxidation is the first result of CCL4-induced liver injury and considered as an indicator of oxidative damage (Basu, 2003; Chiu et al., 2018). MDA is the final product of polyunsaturated fatty acids peroxidation and usually employed as a biomarker of this process (Janero, 1990). In this study, the injection of rats with CCL4 caused a significant elevation in liver MDA levels. While, the levels of hepatic MDA significantly attenuated by the administration of tepals, stigmas and leaves extracts.

Antioxidant compounds have been reported to prevent oxidative damage to the liver and may avoid the risk of liver disease (Bertolami, 2005). Various studies have shown that saffron stigmas, tepals and leaves have antioxidant properties. The stigmas are rich in hydro-soluble carotenoids, mainly crocin and crocetin, while the tepals and leaves are rich in polyphenols and flavonoids compounds (Sánchez-Vioque et al., 2012; Farahmand et al., 2013; Tuberoso et al., 2016). The hepatoprotective effect of the tepals and leaves extract may be due to polyphenols and flavonoids compounds. While the action of stigmas probably due to hydrosoluble carotenoids.

The reinstatement of serum enzyme levels (ALT, AST, ALP and LDH) to normal levels in CCL4 group treated with hydroethanolic extract of different parts of Crocus sativus may indicate prevention of the leakage of intracellular enzymes by stabilizing the hepatic cell membrane. The hepatoprotective effect of Crocus sativus by-products may be due to the improvement of non-enzymatic antioxidant, which plays an important role in maintaining the body's antioxidant defense mechanism, conjugates with free radicals to protect the integrity of cell membranes (He et al., 2012). Also, the increase in the enzymatic antioxidant levels such as superoxide dismutase and catalase can be considered as an efficient defense mechanism to prevent and scavenge the free radical (Bansal et al., 2005).

In addition, hydroethanolic extracts of stigmas, tepals 
and leaves may protects against hepatic fibrosis via multiple protective mechanisms such as the inhibition of CCL4 metabolic activation by blocking the CYP450 enzymatic system, the anti-inflammatory effect of principals compounds, the increase of beneficial restorative macrophages (CD11bhi F4/80int Ly-6Clo) after liver injury, the elevation of MMP9 (type of matrix metalloproteinases) level to regulate extracellular matrix reconstructing after liver injury and the reduction of hepatic stellate cells activation which can transformed into myofibroblast-like cells (Sun et al., 2018). However, the exact protective mechanism(s) of these by-products of Crocus sativus is unknown.

\section{Conclusion}

In conclusion, this suggests that tepals, stigmas and leaves extracts from Crocus sativus have a hepatoprotective effect on CCL4-induced hepatotoxicity in rats. In addition, the hepatoprotective effect of these Crocus sativus by-products could be due to the presence of bioactive molecules with antioxidant properties, which could exert various health benefits.

\section{Acknowledgments}

Many thanks to the Biochemical Analysis Unit of the University Hospital Center (Mohammed VI), Oujda, Morocco. We thank YOUSSEFI Siham and AMIROU Asmae for their assistance in the biochemical analyses. We also thank EL BEDRAOUI Mostapha for his help in the field of animal care.

\section{Conflict of interest}

None of the authors had a conflict of interest.

\section{References}

Ahsan MR, Islam KM, Bulbul IJ, Musaddik MA, Haque E. Hepatoprotective activity of methanol extract of some medicinal plants against carbon tetrachloride-induced hepatotoxicity in rats. Eur J Sci Res 2009; 37: 302-10.

Bansal AK, Bansal M, Soni G, Bhatnagar D. Protective role of vitamin e pre-treatment on n-nitrosodiethylamine induced oxidative stress in rat liver. Chem Biol Interact 2005; 156: 101-11. https://doi.org/10.1016/j.cbi.2005.08.001

Basu S. Carbon tetrachloride-induced lipid peroxidation: eicosanoid formation and their regulation by antioxidant nutrients. Toxicology 2003; 189: 113-27. https://doi. org/10.1016/S0300-483X(03)00157-4
Bertolami MC. Mecanismos de hepatotoxicidade. Arq Bras Cardiol 2005; 85: 25-7.

Burtis CA, Ashwood ER, Hartmann AE. Tietz fundamentals of clinical chemistry. Arch Pathol Lab Med 1999; 123: 646. https://doi.org/10.5858/123.7.646b

Byun JH, Kim J, Choung SY. Hepaprotective effect of standardized ecklonia stolonifera formulation on ccl(4)-induced liver injury in sprague-dawley rats. Biomol Ther 2018; 26: 218. https://doi.org/10.4062/biomolther.2017.199

Callewaert N, Van Vlierberghe H, Van Hecke A, Laroy W, Delanghe J, Contreras R. Noninvasive diagnosis of liver cirrhosis using DNA sequencer-based total serum protein glycomics. Nat Med 2004; 10: 429-34. https://doi. org/10.1038/nm1006

Chiu YJ, Chou SC, Chiu CS, Kao CP, Wu KC, Chen CJ, et al. Hepatoprotective effect of the ethanol extract of polygonum orientale on carbon tetrachloride-induced acute liver injury in mice. J Food Drug Anal 2018; 26: 369-79. https://doi. org/10.1016/j.jfda.2017.04.007

Debnath S, Ghosh S, Hazra B. Inhibitory effect of nymphaea pubescens willd. Flower extract on carrageenan-induced inflammation and ccl4-induced hepatotoxicity in rats. Food Chem Toxicol 2013; 59: 485-91. https://doi.org/10.1016/j. fct.2013.06.036

Farahmand SK, Samini F, Samini M, Samarghandian S. Safranal ameliorates antioxidant enzymes and suppresses lipid peroxidation and nitric oxide formation in aged male rat liver. Biogerontology 2013; 14: 63-71. https://doi. org/10.1007/s10522-012-9409-0

Friedman RB, Anderson RE, Entine SM, Hirshberg SB. Effects of diseases on clinical laboratory tests. Clin Chem 1980; 26: 1D-2D. https://doi.org/10.1093/clinchem/26.4.1D

Ghadami MR, Pourmotabbed A. The effect of crocin on scopolamine induced spatial learning and memory deficits in rats. Physiol Pharmacol 2009; 12: 287-95.

Goli SAH, Mokhtari F, Rahimmalek M. Phenolic compounds and antioxidant activity from saffron (crocus sativus 1.) petal. J Agric Sci 2012; 4: 175. https://doi.org/10.5539/jas. v4n10p175

He J, Huang B, Ban X, Tian J, Zhu L, Wang Y. In vitro and in vivo antioxidant activity of the ethanolic extract from meconopsis quintuplinervia. J Ethnopharmacol 2012; 141: 104-10. https://doi.org/10.1016/j.jep.2012.02.006

Hosseinzadeh H, Ghenaati J. Evaluation of the antitussive effect of stigma and petals of saffron (crocus sativus) and its components, safranal and crocin in guinea pigs. 
Fitoterapia 2006; 77: 446-8. https://doi.org/10.1016/j. fitote.2006.04.012

Hosseinzadeh H, Younesi HM. Antinociceptive and antiinflammatory effects of crocus sativus 1 . Stigma and petal extracts in mice. BMC Pharmacol 2002; 2: 1-8. https://doi. org/10.1186/1471-2210-2-1

Ingawale DK, Mandlik SK, Naik SR. Models of hepatotoxicity and the underlying cellular, biochemical and immunological mechanism(s): a critical discussion. Environ Toxicol Pharmacol 2014; 37: 118-33. https://doi.org/10.1016/j. etap.2013.08.015

Jaishree V, Badami S. Antioxidant and hepatoprotective effect of swertiamarin from enicostemma axillare against d-galactosamine induced acute liver damage in rats. $\mathrm{J}$ Ethnopharmacol 2010; 130: 103-6. https://doi.org/10.1016/j. jep.2010.04.019

Janero DR. Malondialdehyde and thiobarbituric acid-reactivity as diagnostic indices of lipid peroxidation and peroxidative tissue injury. Free Radic Biol Med 1990; 9: 515-40 https:/ doi.org/10.1016/0891-5849(90)90131-2

Kale I, Khan MA, Irfan Y, Veerana GA. Hepatoprotective potential of ethanolic and aqueous extract of flowers of sesbania grandiflora (linn) induced by ccl4. Asian Pac J Trop Biomed 2012; 2: S670-9. https://doi.org/10.1016/ S2221-1691(12)60294-9

Koyama Y, Brenner DA. Liver inflammation and fibrosis. J Clin Invest 2017; 127: 55-64. https://doi.org/10.1172/ JCI88881

Kumar V, Bhat ZA, Kumar D, Khan NA, Chashoo IA, Shah M. Evaluation of anti-inflammatory potential of petal extracts of crocus sativus "cashmerianus". Int J Phytopharm 2012; 3: $27-31$.

Lahmass I, Lamkami T, Delporte C, Sikdar S, Van Antwerpen P, Saalaoui E, et al. The waste of saffron crop, a cheap source of bioactive compounds. J Functl Foods 2017a; 35: 341-51. https://doi.org/10.1016/j.jff.2017.05.057

Lahmass I, Ouahhoud S, Elmansuri M, Sabouni A, Elyoubi M, Benabbas R, et al. Determination of antioxidant properties of six by-products of crocus sativus 1. (saffron) plant products. Waste Biomass Valorization 2017b; 9: 1349-57. https://doi.org/10.1007/s12649-017-9851-y

Lee CP, Shih PH, Hsu CL, Yen GC. Hepatoprotection of tea seed oil (camellia oleifera abel.) against ccl4-induced oxidative damage in rats. Food Chem Toxicol 2007; 45: 888-95. https://doi.org/10.1016/j.fct.2006.11.007

Lin CC, Huang PC. Antioxidant and hepatoprotective effects of acathopanax senticosus. Phytother Res 2000; 14: 489-94.
https://doi.org/10.1002/1099-1573(200011)14:7<489::AID -PTR656>3.0.CO;2-G

Lin YC, Cheng KM, Huang HY, Chao PY, Hwang JM, Lee $\mathrm{HH}$, et al. Hepatoprotective activity of chhit-chan-than extract powder against carbon tetrachloride-induced liver injury in rats. J Food Drug Anal 2014; 22: 220-9. https://doi.org/10.1016/j.jfda.2013.09.012

Lopresti AL, Drummond PD. Saffron (crocus sativus) for depression: a systematic review of clinical studies and examination of underlying antidepressant mechanisms of action. Hum Psychopharmacol, 2014; 29: 517-27. https:// doi.org/10.1002/hup.2434

Manibusan MK, Odin M, Eastmond DA. Postulated carbon tetrachloride mode of action: a review. J Environ Sci Health Part C 2007; 25: 185-209. https://doi. org/10.1080/10590500701569398

Martin FX. Ireland in the time of st. Bernard, st. Malachy, st. Laurence o'toole. Seanchas Ardmhacha. Journal of the Armagh Diocesan Historical Society 1992; 15: 1-35. https:// doi.org/10.2307/29742533

Melnyk JP, Wang S, Marcone MF. Chemical and biological properties of the world's most expensive spice: Saffron. Food Res Int 2010; 43: 1981-9. https://doi.org/10.1016/j. foodres.2010.07.033

Moshiri E, Basti AA, Noorbala AA, Jamshidi AH, Abbasi SH, Akhondzadeh S. Crocus sativus 1. (petal) in the treatment of mild-to-moderate depression: a double-blind, randomized and placebo-controlled trial. Phytomedicine 2006; 13: $607-$ 11. https://doi.org/10.1016/j.phymed.2006.08.006

Ouahhoud S, Lahmass I, Bouhrim M, Khoulati A, Sabouni A, Benabbes R, et al. Antidiabetic effect of hydroethanolic extract of crocus sativus stigmas, tepals and leaves in streptozotocin-induced diabetic rats. Physiol Pharmacol 2019; 23: 9-20.

Papandreou MA, Tsachaki M, Efthimiopoulos S, Cordopatis P, Lamari FN, Margarity M. Memory enhancing effects of saffron in aged mice are correlated with antioxidant protection. Behav Brain Res 2011; 219: 197-204. https:// doi.org/10.1016/j.bbr.2011.01.007

Perrone RD, Madias NE, Levey AS. Serum creatinine as an index of renal function: new insights into old concepts. Clin chem 1992; 38: 1933-53. https://doi.org/10.1093/ clinchem/38.10.1933

Recknagel RO, Glende Jr EA, Dolak JA, Waller RL. Mechanisms of carbon tetrachloride toxicity. Pharmacol Ther 1989; 43: 139-54. https://doi.org/10.1016/01637258(89)90050-8 
Samarghandian S, Borji A. Anticarcinogenic effect of saffron (crocus sativus 1.) and its ingredients. Pharmacogn Res 2014; 6: 99. https://doi.org/10.4103/0974-8490.128963

Sánchez-Vioque R, Rodríguez-Conde MF, Reina-Ureña JV, Escolano-Tercero MA, Herraiz-Peñalver D, SantanaMéridas O. In vitro antioxidant and metal chelating properties of corm, tepal and leaf from saffron (crocus sativus 1.). Ind Crop Prod 2012; 39: 149-53. https://doi. org/10.1016/j.indcrop.2012.02.028

Sánchez-Vioque R, Santana-Méridas O, Polissiou M, Vioque J, Astraka K, Alaiz M, et al. Polyphenol composition and in vitro antiproliferative effect of corm, tepal and leaf from crocus sativus 1 . On human colon adenocarcinoma cells (caco-2). J Funct Foods 2016; 24: 18-25. https://doi. org/10.1016/j.jff.2016.03.032

Serrano-Díaz J, Sánchez AM, Martínez-Tomé M, Winterhalter P, Alonso GL. A contribution to nutritional studies on crocus sativus flowers and their value as food. J Food Compos Anal 2013; 31: 101-8. https://doi.org/10.1016/j. jfca.2013.03.009

Sheng L, Qian Z, Zheng S, Xi L. Mechanism of hypolipidemic effect of crocin in rats: crocin inhibits pancreatic lipase. Eur J Pharmacol 2006; 543: 116-22. https://doi.org/10.1016/j. ejphar.2006.05.038

Smolskaite L, Talou T, Fabre N, Venskutonis PR. Volarization of saffron industry by-products: Bioactive compounds from leaves. Jelgava: Latvia University of Agriculture, Faculty of Food Technology 2011: 67-72.

Sun J, Wu Y, Long C, He P, Gu J, Yang L, et al. Anthocyanins isolated from blueberry ameliorates ccl4 induced liver fibrosis by modulation of oxidative stress, inflammation and stellate cell activation in mice. Food Chem Toxicol
2018; 120: 491-9. https://doi.org/10.1016/j.fct.2018.07.048

Thabrew MI, Joice PD, Rajatissa W. A comparative study of the efficacy of pavetta indica and osbeckia octandra in the treatment of liver dysfunction. Planta Med 1987; 53: 23941. https://doi.org/10.1055/s-2006-962691

Tuberoso CI, Rosa A, Montoro P, Fenu MA, Pizza C. Antioxidant activity, cytotoxic activity and metabolic profiling of juices obtained from saffron (crocus sativus 1.) floral by-products. Food Chem 2016; 199: 18-27. https:// doi.org/10.1016/j.foodchem.2015.11.115

Uemitsu N, Nishimura C, Nakayoshi H. Evaluation of liver weight changes following repeated administration of carbon tetrachloride in rats and body-liver weight relationship. Toxicology 1986; 40: 181-90. https:/doi. org/10.1016/0300-483X(86)90077-6

Vuda M, D’Souza R, Upadhya S, Kumar V, Rao N, Kumar V, et al. Hepatoprotective and antioxidant activity of aqueous extract of hybanthus enneaspermus against ccl4-induced liver injury in rats. Exp Toxicol Pathol 2012; 64: 855-9. https://doi.org/10.1016/j.etp.2011.03.006

Wu SJ, Lin YH, Chu CC, Tsai YH, Chao JC. Curcumin or saikosaponin a improves hepatic antioxidant capacity and protects against ccl4-induced liver injury in rats. $\mathrm{J}$ med food 2008; 11: 224-9. https://doi.org/10.1089/jmf.2007.555

Zeka K, Ruparelia KC, Continenza MA, Stagos D, Veglio F, Arroo RR. Petals of crocus sativus 1 . As a potential source of the antioxidants crocin and kaempferol. Fitoterapia 2015; 107: 128-34. https://doi.org/10.1016/j.fitote.2015.05.014

Zheng CJ, Li L, Ma WH, Han T, Qin LP. Chemical constituents and bioactivities of the liposoluble fraction from different medicinal parts of crocus sativus. Pharm Biol 2011; 49: 756-63. https://doi.org/10.3109/13880209.2010.547206 